\title{
0 Great Game no Sudeste Asiático: a China, a ASEAN e o Mar do Sul da China
}

Nuno Canas Mendes

Professor Associado do Instituto Superior de Ciências Sociais e Políticas (ISCSP) da Universidade de Lisboa (UL) e Presidente do Instituto do Oriente.

\section{Resumo}

A China contemporânea de Xi Jinping, para além de promotora de uma globalização com caraterísticas chinesas, em que a Belt and Road Initiative surge como epítome, tem procurado dominar o seu ambiente de inserção regional no Sudeste Asiático, organizado económica e politicamente em torno da Association of Southeast Asian Nations (ASEAN), convergindo os interesses económicos e estratégicos de uns e de outros no Mar do Sul da China, cuja riqueza em recursos energéticos e piscícolas está na origem de uma disputa de soberania. Acresce que se trata de um espaço por onde passa cerca um terço do comércio mundial. Nesta confluência de rotas marítimas comparam-se os poderes navais e expressa-se igualmente a coexistência competitiva China-EUA, onde se medem forças e a capacidade naval dos EUA, cuja presença e influência no Sudeste Asiático se consolidou durante a Guerra Fria. Nestas circunstâncias - que podem ser descritas como um novo Great Game -, não só a ASEAN não resolve o problema no Mar do Sul da China, como fica sujeita às pressões chinesa e norte-americana num triângulo em que é o elo mais fraco.

Palavras-chave: China; ASEAN; segurança e defesa; Mar do Sul da China; competição estratégica.

\author{
Abstract \\ The "Great Game" in Southeast Asia: China, \\ ASEAN and South China Sea
}

Besides being promoting globalization with Chinese characteristics, with the Belt and Road Initiative as an epitome, Xi Jinping's contemporary China has tried to dominate its regional insertion area and namely Southeast Asia, which is economically and politically organized in the Association of Southeast Asian Nations (ASEAN). Both China and ASEAN have convergent economic and strategic interests in the South China Sea, whose wealth in energetic resources and fisheries is at the origin of a sovereignty dispute. In addition to this, around one-third of world trade passes through this sea. In this confluence of sea-lanes, naval powers are being measured and it is a scenario for the competitive coexistence ChinaUnited States of America, whose influence in Southeast Asia dates from Cold War, where the United States navy capabilities are being tested. In these circumstances - which can be described as a new Great Game -, not only ASEAN does not solve its problems in the South China Sea but also will be positioned in between Chinese and NorthAmerican pressures.

Keywords: China; ASEAN; security and defense; South China Sea; strategic competition.

Artigo recebido: 02.12.2019

Aprovado: 10.12.2019

https: / / doi.org/10.47906/ ND2020.155.06 
A construção de projetos regionais esbarra, frequentemente, com a dificuldade de encontrar nexos, elementos comuns, traços de união e um sentido de coletivo, de comunhão de destino ou, até, mais pragmaticamente, da existência de mínimos denominadores comuns. $\mathrm{O}$ caso do Sudeste Asiático não constitui uma exceção, bem pelo contrário, ainda que na sua evolução cautelosa tenha assumido que o realismo dos objetivos é toldado por questões como os interesses nacionais, a coexistência pacífica ou o papel dos grandes - leia-se China e Estados Unidos da América (EUA) - no terreno. Quase em registo anedótico, foram identificados quatro elementos comuns à região como forma de sublinhar, por contraste, a sua muito expressiva heterogeneidade: a água como vetor de comunicação, a luta anticolonial, a dieta de arroz e a presença generalizada de comunidades chinesas. É certo que na origem e desenvolvimento do projeto o patrocínio norte-americano é um dado incontornável, mas a diáspora dá ao Sudeste Asiático uma tonalidade que "meridionaliza" a China. Os números são impressionantes: cerca de 35 milhões de chineses vivem nos dez países da Association of Southeast Asian Nations (ASEAN), o que representa mais de $80 \%$ da diáspora total $-75 \%$ da população de Singapura, 25\% da Malásia e 15\% da Tailândia (Rocher, 2018). Esta grande família transnacional é agente de um desígnio histórico do Império do Meio de dominar o seu ambiente de inserção regional e um elemento estruturante da cultura diplomática chinesa contemporânea, onde sem rodeios - e a par de uma globalização com caraterísticas "chinesas" como instrumento de competição por influência à escala global - se comporta como o "irmão mais velho", atento e vigilante ao que se passa na vizinhança próxima. E nesta estratégia há um corolário essencial o Mar do Sul da China - que não só é rico em recursos energéticos e piscícolas espalhados pelos milhares de ilhotas, atóis e recifes que a China militariza e coloniza, como, ademais, um espaço por onde passa cerca de um terço do comércio mundial. Nesta confluência de rotas marítimas medem-se os poderes navais e expressa-se, portanto, a coexistência competitiva China-EUA que, no que ao Sudeste Asiático diz respeito, tem raízes antigas na Guerra Fria - que não vêm agora ao caso -, tendo atingido mais recentemente uma nova centralidade, desde o pivot asiático de Obama ao confronto comercial personalizado por Trump (Shambaugh, 2018). A medir forças e a desafiar a capacidade naval dos EUA, a China deixa ao Sudeste Asiático, organizado na ASEAN, uma margem de manobra mais limitada que se traduz na incapacidade de adotar uma "conduta" que concilie os interesses das partes envolvidas, contribuindo, deste modo, para novos realinhamentos e para uma reação orquestrada pelos EUA, que procura dar corpo a uma ideia de Indo-Pacífico, adiante desenvolvida. Para discorrer sobre esta competição estratégica, um triângulo com um dos vértices como elo mais fraco, recorre-se, neste artigo, à sugestiva imagem já aplicada noutros contextos geográficos e históricos: de um "Great Game". 
Vejamos de seguida como se manifesta o cliché, que caraterísticas e peculiaridades assume. Como notou um antigo primeiro-ministro da Austrália (Rudd, 2018, p. 7): “Para a ASEAN isto significa, infelizmente, que estão destinados a viver de facto em tempos interessantes - durante os quais a China procura um flanco sul mais benigno e mais disposto a acomodar os interesses estratégicos chineses e os Estados Unidos procuram preservar as rotas marítimas da Ásia do Sul arquipelágica para liberdade da navegação internacional, assim como a sua própria liberdade de manobra estratégica" ${ }^{\prime 1}$. Conhecidos que são os comportamentos baseados em construção de consensos e a lenta e tíbia evolução institucional da ASEAN, sempre constrangida por mecanismos e lógicas que, se por um lado limitam os resultados e a coesão, por outro têm permitido que o ASEAN Way seja a postura que melhor parece funcionar num tempo em que a hostilidade China-EUA se transformou numa espécie de nova Guerra Fria. Num primeiro passo, a atenção recairá sobre a importância do Mar do Sul da China na relação da China com o bloco ASEAN e no passo seguinte abordar-se-á a desejada e sempre difícil de alcançar "centralidade" da ASEAN.

\section{A importância do Mar do Sul da China na relação da China com a ASEAN}

Muito se tem escrito sobre o lugar ocupado pelo Mar do Sul da China na natureza da relação entre a China - crescentemente mais poderosa tanto no plano naval como no aeronaval - e a ASEAN, dando-se conta das várias dimensões do problema - a disputa de soberania pelas Paracel e as Spratly, com a definição de fronteiras marítimas e de jurisdição sobre as Zonas Económicas Especiais, baseada no interesse pelos recursos em hidrocarbonetos e também na pesca. Num contexto de degradação ambiental e de sobre-pesca, a China envia a sua frota pesqueira para estas águas, protegendo-a com navios de guerra e com guarda costeira, com prejuízo evidente para o Vietname e Filipinas. Seja nas Spratlys seja nas Paracel, a China pôs em marcha uma linha de defesa avançada a $800 \mathrm{Km}$ da costa, com patrulhamento, capacidade de reconhecimento, pistas com capacidade para aviões de combate e caças. Sucede que à complexidade técnica da questão e à tendência de ver nos mecanismos institucionais regionais uma incapacidade constante de alterar significativamente o estado de coisas, se têm de acrescentar os interesses de outros jogadores, nomeadamente dos EUA, para quem a liberdade de navegação neste Mar é considerada um interesse vital de segurança nacional (Council on Foreign Relations, 2019). É esta competição a convergir no Sudeste Asiático o maior foco de tensão regional, afetando simultaneamente o Brunei, as Filipinas, a Indonésia, a Malásia e o Vietname.

1 Tradução do Autor. 
Ora esta questão tem efetivamente um forte peso na estabilidade regional e internacional, na medida em que, como escreve Rocher (2018), avaliando o comportamento chinês: "É também um meio de medir forças com a talassocracia americana que, ela também, através da sua Sétima Esquadra, multiplica as provocações passando nas proximidades das águas chinesas em nome da liberdade de navegação"2

Não se pretendendo neste artigo nem historiar a questão nem abordá-la na sua vertente jurídica, opta-se por centrar a análise no período mais recente privilegiando-se a componente política e securitária. Toma-se, portanto, como início a chegada ao poder de Xi Jinping e a modulação que introduziu na política externa chinesa, a qual, na sua nova assertividade, veio expor novamente os limites de intervenção da ASEAN enquanto grupo, assim como trouxe para a discussão o papel dos EUA na região, neste cenário de enfrentamento crescente entre os dois gigantes. A China de Xi Jinping lançou-se numa comunidade de destino com o Sudeste Asiático, em que a primeira é uma espécie de $11 .^{\circ}$ membro-sombra da ASEAN.

Ao referir-se ao Mar do Sul da China, Donald Weatherbee (2019) classifica-o como motivo para uma crise existencial da ASEAN, considerando que está em cima da mesa a intencionalidade de alterar a disposição estratégica regional em que o hedging foi a postura assumida. A questão põe-se no facto de os desígnios estratégicos e militares da China em relação ao Mar do Sul da China afetarem a tentativa de formular uma resposta comum dos Estados-membros da ASEAN, conforme o espírito de Bali Concord II e a lógica de atuação da Comunidade Política e de Segurança da ASEAN que defende o pressuposto de indivisibilidade estratégica da segurança dos Estados da ASEAN. Mas esta é a história da ASEAN: um debate constante entre se é possível criar e desenvolver um esprit de corps ou se, pragmática e realisticamente, a organização é, antes de mais, uma soma de partes.

Como notou Weatherbee, na ASEAN encontram-se dois ambientes estratégicos, um continental e outro marítimo. Se considerarmos os interesses dos Estados continentais da ASEAN estão sobretudo em causa as ligações à província de Yunnan e não ao Mar do Sul da China, o que obviamente dificulta a obtenção de consensos: "Para tristeza dos Estados-membros cujos direitos no Mar do Sul da China são postos em risco pelas atividades de Pequim, as posições políticas da ASEAN nesta questão refletem um acordo de mínimo denominador comum que evita criticar ou ofender a China"3 (Weatherbee, 2019, pp. 227-228). Países como o Camboja ou

2 Tradução do Autor. Nesta duplicidade e ao abrigo do formato "ASEAN Plus One" foram feitas manobras navais conjuntas entre a ASEAN e a China em 2018 e com os EUA em 2019. Chama-se a atenção para o facto de esta colaboração separada no domínio da cooperação em segurança marítima ser um sinal da capacidade de iniciativa regional (Storey, 2018).

3 Tradução do Autor. 
o Laos, mais dependentes da China, podem ser agentes desse veto, e, de resto, a China explora, como seria de prever, o relacionamento bilateral mais do que o relacionamento com o grupo.

Quando Xi Jinping tomou posse como presidente em 14 de março de 2013 tornou-se claro que havia uma disposição de dar ao relacionamento político com o Sudeste Asiático uma atenção acrescida. Pouco tempo depois, o ministro dos Negócios Estrangeiros, Wang Yi, no seu discurso de 2 de agosto, por ocasião do $10 .^{\circ}$ aniversário da parceria estratégica ASEAN-China, chamava a atenção para a importância da resolução das disputas no Mar do Sul da China: "A China e vários países do Sudeste Asiático têm disputas sobre soberania territorial e direitos e interesses marítimos, herdados da História. Embora não seja um tema central entre a China e a ASEAN, tem na realidade um impacto nas relações entre a China e a ASEAN" (apud Weatherbee, 2019, pp. 248-49), o que trouxe para a mesa das negociações a necessidade de um código de conduta que plasmasse a Declaração de Conduta assinada em 2002 e o reforço pelo primeiro-ministro Li Kequiang em outubro desse mesmo ano: “A China continuará a fazer consultas junto dos países da ASEAN para a formulação de um código de conduta para o Mar do Sul da China (...) de uma maneira ativa e prudente e apoiada no princípio de construção de consensos" (Weatherbee, 2019, p. 248). Em 2016, as Filipinas obtiveram do Tribunal Internacional de Justiça o reconhecimento da soberania sobre o recife de Scarborough, ocupado pela China em 2012, no tempo de Gloria Macapagal-Arroyo, mas Rodrigo Duterte, entretanto eleito presidente (2016), seguiu uma orientação pró-Pequim. O Vietname, em particular, tem sofrido frequentemente a prospeção e o patrulhamento nas suas águas territoriais. Mesmo a Malásia, tradicionalmente mais próxima da China, manifestou as suas preocupações e reservas.

Porém, só aquando da Cimeira ASEAN-China, em novembro de 2017, em conexão

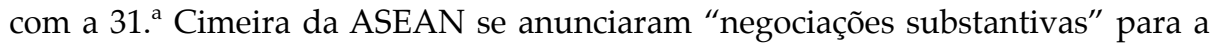
elaboração do referido código de conduta, circulando um draft pouco ambicioso e que avançou já no contexto da presidência filipina da ASEAN - ainda que este país não tenha deixado, no entanto, de reiterar, aquando de uma visita de Trump a Manila, também em 2017, o compromisso com o Acordo de Defesa e Cooperação Reforçada e com o Tratado de Defesa Mútua. Pela parte da Indonésia, o presidente Jokowi não tem feito nenhum esforço visível para a resolução do problema e há um alinhamento claro com a participação no eixo global marítima da Rota da Seda Marítima. Vale a pena acrescentar que atingir um código de conduta consensual não impedirá a China de prosseguir os seus desígnios "imperialistas" nesta questão, dado que esta será apenas e só uma declaração de intenções sem a força das disposições normativas usualmente invocadas, como a Carta das Nações Unidas, os princípios da coexistência pacífica, o Tratado de Amizade e Cooperação do Sudeste Asiático ou a Convenção das Nações Unidas sobre Direito do Mar. Ademais não há nenhuma indicação de quando será finalizado. 
Com o "sonho chinês" em marcha e a inauguração de uma 'nova era' de Xi, o Mar do Sul da China dividiu ainda mais os países, alguns deles recetivos ao investimento chinês nas áreas das infraestruturas e indústria, no âmbito do grande projeto do regime: a Belt and Road Initiative. E a complementaridade económica com a China, associada a uma presença equilibradora dos EUA em termos de segurança está a ser revista, porque o hedging do primeiro decénio do século é agora moldado por uma margem de manobra cada vez mais apertada (ISPI, 2019). Não havendo uma tradição de escolha nem por um nem por outro (Rocher, 2018), a marca de atuação da ASEAN, herdada da Guerra Fria, era deixar as opções em aberto e agora, mais do que nunca, existe o temor de que um ultimato lhes seja feito por uma das partes. Na guerra comercial em curso entre os EUA e a China, tirar vantagens sem alinhar, não permite ignorar que a China é desde 2010 o primeiro parceiro comercial da ASEAN e que em 2018 o volume total das trocas comerciais atingiu um valor de 530 mil milhões de Euros. Os EUA, por seu turno, são o terceiro país com quem a ASEAN faz mais trocas, com um valor estimado em 245 mil milhões de Euros (Rocher, 2018) ${ }^{4}$. Dados que não só não são despiciendos como mostram que as modulações políticas ficam frequentemente reféns desta interdependência.

\section{A "Centralidade" da ASEAN}

O conflito do Mar do Sul da China, expondo as vulnerabilidades do grupo e a tensão entre gigantes, põe em causa a dificuldade de implementar a desejada centralidade da organização quando se exclui da agenda multilateral o que a China pressiona para que fique de fora. O pilar político-securitário, não obstante, cria as condições e as instâncias para um debate alargado, também com as grandes potências, ainda que, no que à resolução de conflitos ou à prevenção de crises, sofra de uma tibieza evidente. Com efeito, esta bipolaridade China-EUA, nas dimensões política, securitária e económica lança para debate um conjunto de preocupações e de atitudes, já aludidas, em que o Sudeste Asiático tenta contornar alinhamentos com um ou com outro e ao não tomar partido a uma paralisia que tem como efeito a necessidade de os Estados da ASEAN lidarem com a falta de um verdadeiro comunitário e o consequente recurso ao apoio externo: as Nações Unidas, os tribunais internacionais ou

4 Não é despropositado lembrar o peso demográfico do bloco ASEAN (645 milhões de pessoas) e que o seu PIB acumulado de 2530 mil milhões de Euros (2018) o torna no quinto bloco mundial e que o seu crescimento médio de 5,1\% desde 2011 a transformou numa região atrativa para o investimento estrangeiro. 
um aliado. Nesta "navegação" fica igualmente claro que a ASEAN não é central nas relações entre as duas potências e que países como a Índia e o Japão se envolvem progressivamente projetando o seu poder e tentando estruturar um novo equilíbrio de poderes, via alinhamento com os EUA, plasmado no recente conceito de Indo-Pacífico e no Diálogo Quadrilateral de Segurança (QUAD), entre os EUA, a Índia, o Japão e a Austrália. É este o contexto em que se procura lançar uma plataforma multilateral para um "Indo-Pacífico Livre e Aberto" como alternativa à China como parceiro para o desenvolvimento, o que não só seria mal recebido em Pequim como provocaria divisão interna no seio da ASEAN.

Em todo o caso a interdependência resultou na adoção do que a ASEAN chamou de "equilíbrio dinâmico", um sistema que exclui um poder preponderante e que privilegia a estabilidade e a cooperação com os EUA e a China, muito embora o conceito enferme de fragilidades evidentes: a disposição veemente da China em transformar o Sudeste Asiático numa esfera de influência e a ameaça de que os interesses económicos da ASEAN seriam prejudicados com a insistência de internacionalizar, o que a China insiste ser uma disputa de natureza bilateral.

É certo que apesar de ter sido criado um dispositivo de fora diplomáticos no seio da ASEAN, incluindo o Fórum Marítimo da ASEAN, ainda que mais do que encontrar uma resposta comum para enfrentar a China se definam linhas de divisão no interior da própria organização. No plano bilateral, há algumas mudanças recentes a registar: o acordo de defesa entre a China e Singapura, assinado a 20 de outubro de 2019 (Parameswaran, 2019), que reforça o compromisso e que resume uma conjugação de fatores para os quais contribuem a crescente assertividade chinesa, a competição China-EUA e a acomodação de uma nova geração de líderes políticos em Singapura. Ora este tipo de abordagem é só uma manifestação clara de que a China pretende redimensionar a arquitetura de segurança regional através do estabelecimento de novas parcerias de defesa na região, parcerias estas que incluem novos "acordos, diálogos e facilidades" que tenderão a densificar o relacionamento (Parameswaran, 2019). Singapura assume muito abertamente este compromisso e considera negativa a subida de tom no confronto entre Pequim e Washington ${ }^{5}$.

Outra dimensão fundamental desta questão é o estabelecimento de nexos com as grandes potências da região, nomeadamente com países como a Índia, o Japão

5 O ministro da Defesa de Singapura, Ng Eng Hen, declarou publicamente que o custo de um conflito no Mar do Sul da China seria demasiado elevado (Shams, 2019). 
ou a Austrália (Rudd, 2018). É aqui que podemos discutir se está em formação uma deriva em torno de um eixo do Indo-Pacífico. Na reconfiguração recente que a competição entre os EUA e a China tem produzido, é importante conhecer a reação dos Estados-membros e da própria ASEAN à ideia de um Indo-Pacífico Livre e Aberto. Promovida acima de tudo pelos EUA, esta ideia pode ter implicações na centralidade da ASEAN e na sua arquitetura de segurança, nomeadamente porque exerce pressão adicional às posturas tradicionais, desde o não-alinhamento e o hedging até à sempre evitada e potencialmente dolorosa decisão de tomar partido. Em certa medida, a não surpreendente ambiguidade não pode ser desligada do facto de o Diálogo Quadrilateral de Segurança (Quad) acusar uma falta de concertação e de propósito comum. A seletividade ambivalente nos nexos externos pressupõe uma adaptabilidade e realinhamentos casuísticos, em que se tenta cultivar uma equidistância, com base num cálculo constante de perdas e ganhos. Ora, como se sabe, a Índia tem, desde a sua Look East Policy e agora de forma mais exuberante durante a administração Modi, um ascendente importante no Sudeste Asiático. No contexto da contida competição China-Índia, a ASEAN remete-se ao seu posicionamento não habitual de ser recetiva sem se comprometer demasiado, ainda que o envolvimento crescente dos EUA com a Índia seja outra forma de exercício de pressão com que a organização e o grupo terão de lidar.

Com efeito, a centralidade da região Ásia-Pacífico nas relações internacionais e o lugar cimeiro da China induz quase intuitivamente a olhar para a Índia como o contrapeso, a competir no espaço do Índico. Com uma demografia favorável e um crescimento económico auspicioso, tem despertado um interesse crescente para o estabelecimento de alianças: Estados Unidos e Japão à cabeça, mas outros como a Austrália, Singapura ou mesmo a França jogam o jogo clássico do balance of power, para deter o que poderíamos classificar como "abuso de posição dominante" chinês. Para além de amplamente envolvida com o Paquistão, a China tem desenvolvido laços com países tradicionalmente incluídos na esfera de influência da Índia, como o Sri Lanka, o Nepal ou as Maldivas e apostado na criação de instituições financeiras locais, como o Asian Infrastructure Investment Bank, para além de ter uma balança comercial favorável e de não ter sido ultrapassada a disputa fronteiriça - em Arunashal Pradesh, do lado indiano, e no Tibete, do lado chinês -, ainda que, apesar de tudo, persista como nota dominante no diálogo entre os rivais a cordialidade. A Índia resiste a uma formalização das alianças, numa espécie de não comprometimento que convive com a ambiguidade ditada pela necessidade, ao mesmo tempo que se procura aumentar a sua capacidade de influência à escala global, embora numa posição negocial de uma assertividade que toca, em alguns temas, a inflexibilidade. Em 2003, Subrata K. Mitra, chamava-lhe reluctant hegemon. 
Embora o discurso de Modi, em apoio de um vigoroso nacionalismo, aponte para a defesa da integração económica e do reforço do comércio, têm sido adotadas medidas de caráter protecionista e criados obstáculos à conclusão de vários acordos, com efeitos expressivos numa característica em que a China leva de novo a melhor: a conectividade ${ }^{6}$.

De ressaltar que a estratégia Free and Open Indo-Pacific, não tem um conteúdo muito claro e tem sido encarada como uma forma de conter as capacidades da China de domínio das águas, comércio e diplomacia asiáticas. Põe ênfase na soberania dos Estados, secundarizando coligações multilaterais coerentemente com a postura "nacionalista" de Trump. A ideia de promover laços com as três "outras" potências - Japão, Índia e Austrália - inscreve-se na lógica de conter a assertividade chinesa e a abordagem bilateral, em substituição da multilateral falhada com a "queda" da Parceria Trans-Pacífico. De referir que o Japão lançou uma aliança informal e implicitamente anti-chinesa, "The Quad", que inclui a Índia, a Austrália e os Estados Unidos - quadrilateral security dialogue, proposta de Shinzo Abe, lançada em 2007 e reanimada nas cimeiras da ASEAN e da Ásia Oriental de 2017, em Manila; no quadro da Quad têm ocorrido conversações no sentido de apresentar uma alternativa à Belt and Road Initiative, com o Japão a defender uma Free and Open Indo-Pacific Strategy mais ampla, incluindo infraestruturas de elevada qualidade.

6 Desde que Modi assumiu a liderança, em maio de 2014, que tem procurado dar à Índia uma maior projeção global. Começou por lançar o Neighbourhood First para se aproximar dos mais próximos geograficamente e lançou o Act East direcionado para o Sudeste Asiático, estreitando laços com a ASEAN ou com a Bay of Bengal Initiative for Multi-Sectoral Technical and Economic Cooperation (BIMSTEC), que agrega o Bangladesh, a Índia, o Myanmar, o Sri Lanka, a Tailândia, o Nepal e o Butão e pretende ser um acordo de comércio livre. Outro vetor fundamental é a política marítima e a aposta na formação de uma região Indo-Pacífico, sendo que $90 \%$ do volume e $77 \%$ do valor do comércio internacional é feito por mar. Claro que esta equação não pode ser separada de a China ter também ela uma presença crescente no Índico, ameaçando claramente a supremacia da Índia numa esfera de influência tradicionalmente sua. A Belt and Road Initiative, apostada na cooperação e na conectividade, mas sustentada igualmente em atividade militar no Índico, a sua atividade vincada na região dos Himalaias - a disputa com o Butão pelo planalto de Doklam - e as relações com os vizinhos da Índia, em especial com o Paquistão mediante a construção do corredor económico China-Paquistão, através de Caxemira, criam o desconforto do "cerco". Não obstante, as relações comerciais com a China, que é o seu segundo parceiro depois da UE, são para continuar sólidas e em alguns tabuleiros diplomáticos há convergência, como seja o apoio à entrada na Organização de Cooperação de Xangai (2017) ou a participação no Asian Infrastructure Investment Bank, de que detém 7,5\%. 


\section{Notas Conclusivas}

Como referiu Shambaugh (2018), a competição sino-americana no Sudeste Asiático não é nem "aguda" nem de "soma zero". O Sudeste Asiático surge como um epicentro da mesma e está posto perante uma pressão crescente nesta competição, que não só não pode ignorar como procura aproveitar em seu benefício - do ponto de vista económico, países como o Vietname e, em menor escala, a Tailândia e a Indonésia, têm lucrado com a guerra comercial em curso.

O desenvolvimento institucional ocorrido no seio da ASEAN no âmbito da paz e segurança expõe os limites do soft power (Patel, 2019). Acima de tudo o que ficou definido na declaração de 2012 (Bali Concord II) carece de uma consubstanciação que a não-intervenção, o consenso e o não uso da força - a herança da coexistência pacífica plasmada no ASEAN Way - acabam por limitar, comprometendo uma abordagem coerente às crises e às inúmeras questões de segurança - terrorismo transnacional, refugiados, migrações, tráficos vários, etc. Mas esta é ao mesmo tempo a condição de sobrevivência e a chave para a sua continuidade e resultados alcançados. E se é verdade que as insuficiências estão identificadas, também ainda não se encontraram lógicas ou mecanismos de intervenção diversos dos existentes. Mesmo que algum dos Estados-membros lance uma ameaça com efeito sobre os outros, tem a garantia de que as reações podem ser limitadas, em última análise, por um veto do próprio. E esta tem sido a marca de uma organização em que as sucessivas crises, discutidas nos fora próprios, com parceiros internacionais sublinhe-se a importância do Fórum Regional da ASEAN e da noção de diplomacia preventiva -, têm sido maioritariamente ultrapassadas internamente. Muito recentemente, a crise dos Rohingya, no Myanmar, ilustra bem esta caraterística: a postura não-confrontacional não conseguiu estancar a deslocação forçada deste povo para o Bangladesh.

Como noutras ocasiões sucedeu, alguns Estados-membros procuraram usar os mecanismos bilaterais (caso da Indonésia) ou assumiram uma posição abertamente crítica (caso da Malásia). No coletivo, o statu quo manteve-se. E no que toca ao Mar do Sul da China, como se viu ao longo do artigo, a procura de uma solução pacífica para esta disputa de direitos, lançada em 1992, só evoluiu para uma Declaração de Conduta atingida em 2012, e na decisão de avançar para um Código de Conduta sem conclusão à vista. Neste desfavor do multilateralismo, o bilateralismo e as dissonâncias entre Estados-membros têm beneficiado a China - o já citado caso do Camboja e do bloqueio a uma declaração conjunta da organização em 2016.

Uma ASEAN descentrada no funcionamento, mas central na confluência de interesses dos grandes do mundo, é uma ASEAN a gerir um dilema existencial mais agudo neste momento, mas que é uma espécie de pecado original de que não se libertou. 


\section{Referências Bibliográficas}

Council on Foreign Relations, 2019. What is ASEAN? Disponível em: https:/ /www.cfr.org/ backgrounder/what-asean. Consultado em 10.01.2020.

Istituto per gli Studi di Politica Internazionale, 2019. China-Southeast Asia Relations: From the Cold War to the "New Era", 27 September. Disponível em: https:/ / www.ispionline.it/en/ pubblicazione/ china-southeast-asia-relations-cold-war-new-era-24019. Consultado em 10.01.2020.

Parameswaran, P., 2019. Why the new China Singapore defense agreement matters. The Diplomat, 23.10. Disponível em: https: / / thediplomat.com/2019/10/ why-the-new-china-singapore-defense-agreement-matters/. Consultado a 07.01.2020.

Patel, C., 2019. Embrace Soft Power (but Recognize its Limits). Chatham House, 12 june. Disponível em: https://www.chathamhouse.org/expert/comment/embrace-soft-powerrecognize-its-limits. Consultado em 05.01.2020.

Rocher, S. B., 2018. La coopération chinoise en matière d'armement vers les pays de l'ASEAN: une diplomatie d'influence, in Revue de Défense Nationale, n. ${ }^{\circ}$ 812, pp. 106-111.

Rudd, K., 2018. The United States, China and Southeast Asia: Can ASEAN find a New Strategic Equilibrium? Asia Society Policy Institute. Disponível em: https:/ / asiasociety.org/policy-institute / united-states-china-and-southeast-asia-can-asean-find-new-strategic-equilibrium. Consultado em 10.01.2020.

Shambaugh, 2018. US-China rivalry in south-east Asia: power shift or competitive coexistence? International Security, 42(4), Spring, pp. 85-127.

Shams, S., 2019. Singapore defense minister: Cost of conflict in South China Sea 'too high'. Deutsch Welle, Interview (19.02). Disponível em: https://www.dw.com/en/singaporedefense-minister-cost-of-conflict-in-south-china-sea-too-high/a-47568024. Consultado a 05.01.2020.

Storey, I. e Cook, M., 2018. The Trump administration and south-east Asia: America's Asia policy crystallizes, Perspective no. 77, Singapore: ISEAS Yusof Ishak Institute, 29 Nov. Disponível em: https: / / www.iseas.edu.sg/articles-commentaries/iseas-perspective/item/9225201914-the-trump-administration-and-southeast-asia-the-hanoi-summit-and-us-policyin-southeast-asia-by-malcolm-cook-and-ian-storey. Consultado em 06.01.2020.

Tan, S. S., 2020. Consigned to hedge: south-east Asia and America's 'free and open Indo-Pacific' strategy. International Affairs, Volume 96, Issue 1, January, pp. 131-148. Disponível em: https: / / doi.org/10.1093/ia/iiz227

Weatherbee, D. E., 2019. ASEAN's Half Century: A Political History of the Association of Southeast Asian Nations. London: Rowman \& Littlefield.

Weatherbee, D. E., 2015. International Relations in Southeast Asia, The Struggle for Autonomy, $3^{\text {rd }}$ edition. London: Rowman \& Littlefield. 